\title{
Efficacy, Safety, and Tolerability of Valsartan/ Hydrochlorothiazide in Asian Patients with Essential Hypertension
}

Wen-Ter Lai · Jeong-Euy Park · Neelesh Dongre · Jackson Wang

Received: November 2, 2010 / Published online: April 8, 2011

(C) The Author(s) 2011. This article is published with open access at Springerlink.com

\section{ABSTRACT}

Introduction: Previous studies have demonstrated that hypertensive patients need concomitant therapy with one or more drugs from different classes of antihypertensive agents to achieve their blood pressure control targets. We performed the first multinational observational study of valsartan/hydrochlorothiazide (HCTZ) single pill combination in Asia to determine the efficacy, safety, and tolerability in hypertensive patients. The objective of this multinational, multicenter, 24-week follow-up observational study is to evaluate the efficacy, safety, and

\footnotetext{
Wen-Ter Lai $(\bowtie)$

100 Tzyou 1st Road, Division of Cardiology,

Department of Internal Medicine, Kaohsiung

Medical University Hospital, Kaohsiung 807,

Taiwan. Email: wtlai@cc.kmu.edu.tw

Jeong-Euy Park

Cardiology Division, Samsung Medical Center,

Seoul, Korea

Neelesh Dongre

Scientific Operations Department, Asia-Pacific,

Middle East \& African Countries, Novartis Pharma AG,

Basel, Switzerland

Jackson Wang

Scientific Operations Department, Novartis (Taiwan)

Co., Ltd., Taipei, Taiwan
}

tolerability of valsartan/hydrochlorothiazide single pill combination in the treatment of essential hypertension in the Asia-Pacific region. Methods: A total of 7567 Asian patients who were diagnosed with stage 1 or stage 2 essential hypertension and who took at least one dose of valsartan/hydrochlorothiazide single pill combination were included in the statistical analyses. A total of 59\% were taking antihypertensive medication at the time of the study. Eligible patients received valsartan/ hydrochlorothiazide single pill combination $80 / 12.5 \mathrm{mg}$ tablets orally once daily at visit 1 . The investigator could decide the subsequent dose of valsartan/hydrochlorothiazide single pill combination for their patients, and efficacy, safety, and tolerability data were collected at week 4, 12, and 24. Results: Basal blood pressure was $155.9 \pm 13.3 \mathrm{mmHg}$ (systolic) and $96.3 \pm 10.1 \mathrm{mmHg}$ (diastolic). Response rates and control rates increased continuously from baseline to the study endpoint at week 24 , when they reached $94.6 \%$ and $73.2 \%$, respectively. Systolic and diastolic blood pressure reductions were $-25.4 \pm 15.2 \mathrm{mmHg}$ and $-14.9 \pm 13.5 \mathrm{mmHg}$, respectively $(P<0.001)$. Using a four-point global assessment scale, $96.8 \%$ of the patients and physicians reported good, very good, or 
excellent for both their subjective efficacy and tolerability assessments. Conclusion: In this multicenter, multicountry study including 7567 Asian patients with hypertension, valsartan/ hydrochlorothiazide single pill combination was found efficacious, well tolerated, and devoid of any serious adverse effects.

Keywords: Asian; combination therapy; efficacy; hypertension; tolerability; valsartan/ hydrochlorothiazide single pill

\section{INTRODUCTION}

Hypertension is the most common cardiovascular condition in the world and is the leading preventable cause of morbidity and mortality due to coronary heart disease, stroke, heart failure, and kidney failure. ${ }^{1}$ In the urban adult populations of Asia, the prevalence, using the criterion of blood pressure (BP) $\geq 140 / 90 \mathrm{mmHg}$, varies between $15 \%$ and $35 \%$, although it is lower in rural areas. ${ }^{2-4}$ Despite the availability of a wide range of antihypertensive drugs, mild to moderate hypertension still remains poorly controlled. ${ }^{5}$ Inadequate lowering of BP with antihypertensive therapy can be attributed to several factors, such as multiple pathophysiological mechanisms involved and the heterogeneity among patients, the failure of physicians to titrate or modify first-line therapy to reach the recommended target $\mathrm{BP}$, and the lack of patient compliance. ${ }^{6}$

Despite the efficacy of monotherapy with a number of antihypertensive agents, approximately $70 \%$ of hypertensive patients require one or more antihypertensive drugs with different mechanisms of action in order to reach treatment targets. ${ }^{7}$ Therefore, the Joint National Committee on Prevention, Detection, Evaluation, and Treatment of High Blood Pressure (JNC) and the World Health Organization (WHO) have recently recommended combination therapy as a first-line approach for stage 2 hypertension. ${ }^{8}$ Combination therapy also has the advantage of achieving improved antihypertensive efficacy at low individual drug doses compared with those used in monotherapy and, therefore, has a lower incidence of adverse effects. ${ }^{8}$

Valsartan, an angiotensin II receptor blocker (ARB), lowers BP mainly by blocking the effects of angiotensin II on vascular smooth muscle. ${ }^{9}$ It also blocks the aldosterone-mediated retention of sodium and excretion of potassium in the distal tubule by preventing angiotensininitiated aldosterone release from the adrenal gland.

Hydrochlorothiazide (HCTZ), a thiazide diuretic, is thought to lower BP primarily by decreasing sodium resorption in the renal distal convoluted tubules. ${ }^{10,11}$ This sodium depletion causes a reflex increase in plasma renin activity, a subsequent increase in angiotensin, and in aldosterone secretion, and urinary retention of sodium accompanied by excretion of potassium. Therefore, coadministration of an angiotensin II receptor antagonist like valsartan can lessen the potassium loss associated with the use of thiazide diuretics. ${ }^{12}$

Increasing amounts of evidence have confirmed that combination therapy is the preferred treatment regimen to achieve satisfactory control of BP in the majority of hypertensive patients. ${ }^{7,8}$ The combination of an ARB and low-dose HCTZ does not produce any major side effects and provides an antihypertensive action significantly greater than that of either drug given alone. ${ }^{12-16}$ The objective of this multinational observational study is to further evaluate the efficacy, safety, and tolerability of valsartan/HCTZ single pill combination (SPC) in the treatment of essential hypertension in a general clinical practice setting. The study design was selected with the 
aim to collect data from real-world practice with a substantial cohort of Asian patients representative of the population being prescribed valsartan/HCTZ SPC in the Asia-Pacific region.

\section{MATERIALS AND METHODS}

\section{Study Objectives}

This multinational, open-label, observational, noncomparative, clinical decision-based titration study was conducted at 371 centers in Asia, including Bangladesh, India, Indonesia, Korea (South), Malaysia, Pakistan, Taiwan, and Thailand. A total of 8557 patients were enrolled in the study. Of these patients, 7567 took at least one dose of valsartan/HCTZ SPC and were included in the statistical analysis, with 6852 completing the study (Figure 1). Inclusion criteria were (1) male or female subjects $\geq 18$ and $\leq 65$ years of age; (2) naïve patients with stage 1 (systolic blood pressure [SBP] 140-159 $\mathrm{mmHg}$ / diastolic blood pressure [DBP] 90-99 $\mathrm{mmHg}$ ) or stage 2 (SBP $\geq 160 \mathrm{mmHg} / \mathrm{DBP} \geq 100 \mathrm{mmHg}$ ) essential hypertension, or patients uncontrolled on current monotherapy or other combination therapy. Exclusion criteria were (1) women who were pregnant, intending to become pregnant or who were breastfeeding; (2) subjects with severe medical conditions that in view of the investigator prohibited participation in the study (eg, severe renal or hepatic impairment); and (3) hypersensitivity to valsartan/HCTZ SPC or any of the components in the formulation.

Figure 1. Study flow chart. ITT=intent to treat; $\mathrm{PP}=$ per protocol.

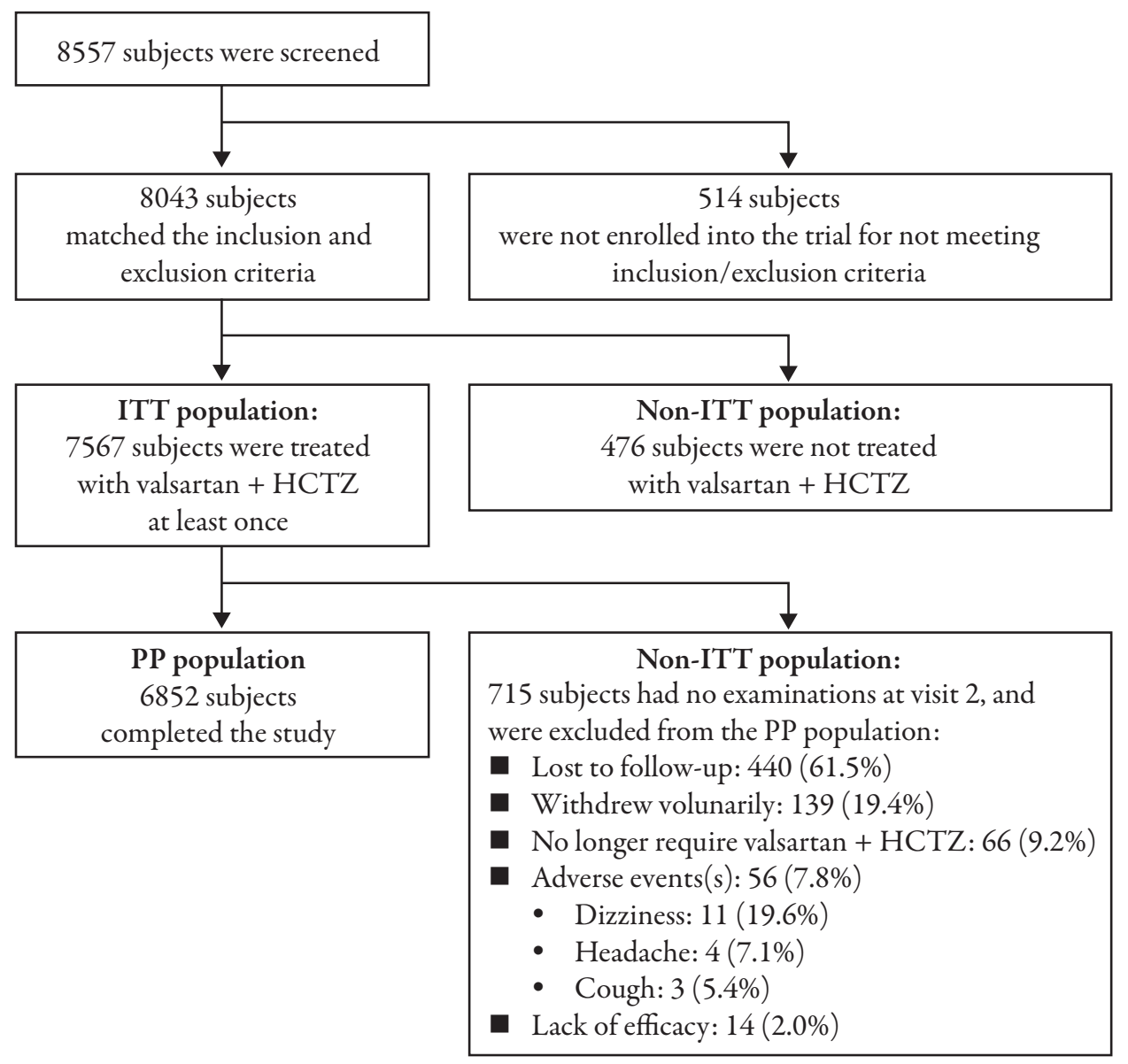




\section{Baseline Antihypertensive Medications}

Of the 13,936 records for baseline medications, 3450 were for antihypertensive therapy and 10,119 for nonantihypertensive therapy, and the medications named in the remaining $367(2.6 \%)$ records could not be reliably identified.

A total of $2106(27.8 \%)$ were taking antihypertensive medication at the start of the study. About one-half (1193 patients, 56.6\%) were on one, 609 patients (28.9\%) on two, 221 patients $(10.5 \%)$ on three, 56 patients $(2.7 \%)$ on four, and 27 patients (1.3\%) on more than four antihypertensive medications at baseline. Of these patients, 2,053 (97.5\%) were taking antihypertensive medications that were not diuretics, and $210(10.0 \%)$ of them were taking diuretics.

Of the 2053 patients who were taking antihypertensive medications that were not diuretics, 1409/2053 (68.6\%) were taking a calcium channel blocker, 1114/2053 (54.2\%) were taking beta blockers, 222/2053 (10.8\%) were taking alpha blockers, 148/2053 (7.2\%) were taking an angiotensin-converting enzyme inhibitor (ACEI), 72/2053 (3.5\%) were taking an ARB, 11/2053 $(<1 \%)$ were taking alpha 2 agonists, and 10/2053 (<1\%) were taking direct vasodilators.

Of the 210 patients who were taking diuretics, $68 / 210(32.4 \%)$ were taking high-ceiling diuretics, 44/210 (21.1\%) were taking potassiumsparing diuretics, 34/210 (16.2\%) were taking loop diuretics, 37/210 (17.6\%) were taking thiazide-type diuretics, and 21/210 (10.0\%) were taking low-ceiling diuretics.

Diagnosis of hypertension was based on JNC 7 guidelines ${ }^{17}$ stage 1 (SBP 140-159 mmHg/DBP 90-99 $\mathrm{mmHg}$ and stage 2 (SBP $\geq 160 \mathrm{mmHg} / \mathrm{DBP}$ $\geq 100 \mathrm{mmHg}$ ). As this was a noninterventional study, previous antihypertensive therapy could be continued according to the discretion of the clinician. If the previous antihypertensive treatment duplicated the study drug treatment, the patients were switched from the original treatment in order to be enrolled in this study. The measurement of BP was performed according to usual clinical practice (Korotkoff sound for one-time sitting BP measurement or average BP of three-sitting BP measurement). The total duration of treatment with valsartan/HCTZ SPC was 24 weeks. All patients signed informed consent forms at the first visit.

The primary objective of the study was to evaluate the efficacy of valsartan/HCTZ SPC $80 / 12.5 \mathrm{mg}, 160 / 12.5 \mathrm{mg}$, and 160/25 mg based on the percentage of responders. Responders were defined as those with SBP $<140 \mathrm{mmHg}$ and/ or DBP $<90 \mathrm{mmHg}$ or a reduction of $>10 \mathrm{mmHg}$ in DBP and/or $>20 \mathrm{mmHg}$ in SBP compared to baseline values at week 24 . The secondary objectives of the study were to evaluate the reduction in SBP and DBP, to assess the $\mathrm{BP}$ control rate (percentage of patients whose BP had reached the control values of SBP $<140 \mathrm{mmHg}$ and DBP $<90 \mathrm{mmHg}$ ), to obtain subjective assessments by patients and physicians of the efficacy and tolerability of valsartan/HCTZ SPC at week 24 , and to monitor safety throughout the study period.

\section{Treatment}

At visit 1 (week 0), eligible patients received a prescription for valsartan/HCTZ SPC 80/12.5 mg tablets orally once daily. At visit 2 (week 4 ), the investigator decided on the subsequent dose of valsartan/HCTZ SPC to be taken, based on the BP control achieved by the initial dose. If the BP was not controlled (defined as DBP $\geq 90 \mathrm{mmHg}$ and/ or SBP $\geq 140 \mathrm{mmHg}$ ), the dose of valsartan/HCTZ SPC was increased to $160 / 12.5 \mathrm{mg}$ or $160 / 25 \mathrm{mg}$ once daily, and this dose was continued until either the next visit or the end of the study; (2) if 
the BP was controlled (DBP $<90 \mathrm{mmHg}$ and/or SBP $<140 \mathrm{mmHg}$ ), the dose of valsartan/HCTZ SPC could also be modified to $160 / 12.5 \mathrm{mg}$ or $160 / 25 \mathrm{mg}$ if, in the investigator's clinical judgment, a further reduction in BP would be beneficial for the patient.

At all subsequent visits, visits 2 (week 4), visit 3 (week 12) and visit 4 (week 24), the investigator could modify the dose of valsartan/ HCTZ SPC, based on the BP control achieved and the tolerability of the dosage used. If at any visit the patient's BP was not controlled with the maximum dose of valsartan/HCTZ SPC, the investigator had the option of adding another suitable antihypertensive, based on clinical judgment and experience. All concomitant therapy was allowed at the discretion of the investigators.

\section{Outcome Measurement}

Clinical outcome was measured in terms of the reduction in SBP and DBP. Mean \pm SD reductions in SBP and DBP were calculated from baseline (week 0) to the end of treatment (week 24). The $\mathrm{BP}$ control rate was defined as percentage of patients achieving the designated control BP (SBP $<140 \mathrm{mmHg}$ and DBP $<90 \mathrm{mmHg}$ ). This rate was calculated using the frequency distribution at the end of treatment (week 24). Global assessment of efficacy and tolerability were both evaluated by physicians and patients using a four-point scale (excellent, very good, good, and poor). Frequency distribution was used to perform the analysis of these parameters at week 24. An adverse event was defined as any untoward medical occurrence or clinical investigation in a patient administered a pharmaceutical product and did not necessarily have a causal relationship to the treatment. Worsening of signs and symptoms present at the initial visit and the appearance of new signs and symptoms after valsartan/
HCTZ SPC administration were considered as adverse events. We did not examine potassium or creatinine levels or investigate coughs specifically, nor did we determine the percentage of diabetic patients in this cohort.

\section{Statistical Analysis}

Categorical variables were presented as counts and percentages, and the chi-square test was used to test the associations between categorical variables; continuous variables were presented as mean \pm SD. SBP and SBP reductions between females and males were compared by independent two-sample $t$ test. Repeated analysis of covariance was performed to detect differences in BP between the initial and the four treatment time points. A paired $t$ test was performed to detect the difference in BP between two time points. Cohen's kappa was performed to demonstrate agreement of the global assessments for efficacy and tolerability between the patient and their physician (Cohen's kappa: 0-0.2, slight agreement; 0.2-0.4, fair agreement; 0.4-0.6, moderate agreement; 0.6-0.8, substantial agreement; 0.8-1.0, almost perfect agreement) with a significance level set at 0.05. Statistical analyses were performed using SPSS 15.0 software (SPSS Inc, Chicago, IL, USA).

\section{RESULTS}

\section{Baseline Characteristics}

All 7567 patients who took at least one dose of valsartan/HCTZ SPC were included in the statistical analysis. Patient demographics and baseline characteristics are shown in Table 1. In all, $55 \%$ of patients had stage 2 and $45 \%$ stage 1 hypertension. The mean BP values at baseline were $155.9 \pm 13.3 \mathrm{mmHg}$ (SBP) and 96.3 \pm 10.1 mmHg (DBP). All patients were Asian, with the 
Table 1. Patient demographics and baseline characteristics.

\begin{tabular}{lc}
\hline Characteristic & Total $(n=7567)$ \\
\hline Sex, $n(\%):$ & \\
$\quad$ Female & $3147(41.6)$ \\
$\quad$ Male & $4420(58.4)$ \\
Age, years $($ mean \pm SD) & $52.8 \pm 8.3$ \\
Height, cm (mean \pm SD) & $163.0 \pm 12.4$ \\
Weight, $\mathrm{kg}($ mean \pm SD) & $69.4 \pm 12.6$ \\
SBP, mmHg (mean \pm SD) & $155.9 \pm 13.3$ \\
DBP, mmHg (mean \pm SD) & $96.3 \pm 10.1$ \\
HR, beats per minute $($ mean $\pm S D)$ & $76.2 \pm 11.8$ \\
Country, $n(\%):$ & \\
Korea & $3420(45.2)$ \\
Taiwan & $2493(32.9)$ \\
Pakistan & $741(9.8)$ \\
Bangladesh & $392(5.2)$ \\
India & $240(3.2)$ \\
Indonesia & $235(3.1)$ \\
Malaysia & $46(0.6)$ \\
\hline
\end{tabular}

$\mathrm{DBP}=$ diastolic blood pressure; $\mathrm{HR}=$ heart rate;

$\mathrm{SBP}=$ systolic blood pressure.

following country distribution: Korea (45.2\%), Taiwan (32.9\%), Pakistan (9.8\%), Bangladesh (5.2\%), India (3.2\%), Indonesia (3.1\%), and Malaysia (0.6\%).

\section{Efficacy and Tolerability of Valsartan/HCTZ SPC}

The dose of valsartan/HCTZ SPC in the 0-4 week period was $80 / 12.5 \mathrm{mg}$ for all patients. In the 4-12 week period, $82.3 \%$ of patients were continued on this dosage, $14.4 \%$ were titrated to a $160 / 12.5 \mathrm{mg}$ dosage, and $2.6 \%$ to a $160 / 25 \mathrm{mg}$ dosage. In the $12-24$ week period, the percentage of patients taking the low, initial dosage form remained unchanged $(82.3 \%)$, the percentage taking the medium dosage form increased slightly (to 16\%) and the percentage taking the highest dosage decreased slightly (from $2.6 \%$ to $1.8 \%$ ). SBP and DBP decreased continuously and significantly throughout the study period (Figure 2) (all $P$ values $<0.05$ ), and were $155.9 \pm 13.3 \mathrm{mmHg}$ and $96.3 \pm 10.1 \mathrm{mmHg}$, respectively (at baseline, $140.7 \pm 13.3 \mathrm{mmHg}$ and $87.2 \pm 9.5 \mathrm{mmHg}$ at week 4 , $134.7 \pm 12.1 \mathrm{mmHg}$ and $83.8 \pm 13.1 \mathrm{mmHg}$ at week 12 , and $130.5 \pm 11.4 \mathrm{mmHg}$ and $81.5 \pm 11.8 \mathrm{mmHg}$ at week 24).

Response rates, $\mathrm{BP}$ control rates, and $\mathrm{BP}$ reductions are summarized in Table 2 . Response rate and control rate increased continuously from baseline to the end of the study, week 24 , when they reached $94.6 \%$ and $73.2 \%$, respectively. Mean SBP and DBP reductions were $-25.4 \pm 15.2 \mathrm{mmHg}$ and $-14.9 \pm 13.5 \mathrm{mmHg}$, respectively at the end of the study (week 24, $P<0.001)$. Significant reductions compared to baseline values in both SBP and DBP were also seen at weeks 4 and $12(P<0.001)$.

The global subjective efficacy assessment for valsartan/HCTZ SPC is summarized in Table 3.1. Almost all patients and physicians (96.8\%) reported good, very good, or excellent for efficacy, and $80.6 \%$ of the patients reported the same global efficacy assessment as their physicians.

Figure 2. Serial changes in systolic blood pressure (SBP) and diastolic blood pressure (DBP) (mean \pm SD) from baseline to week 24 . ${ }^{*}$ Indicates a significant difference in blood pressure compared to baseline ( $P$ values $<0.05$ ). †Indicates a significant difference in blood pressure compared to week 4 visit $(P$ values $<0.05)$. $\neq$ Indicates a significant difference in blood pressure compared to week 12 visit $(P$ values $<0.05)$.

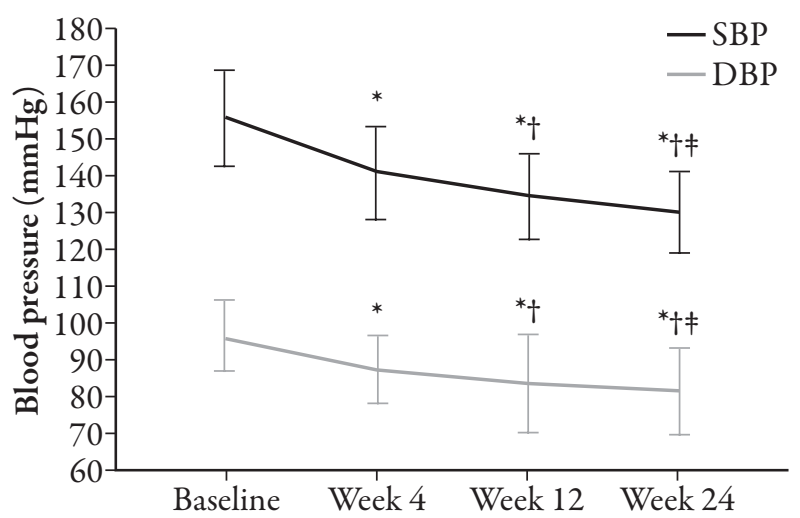


Table 2. Efficacy endpoints at weeks 4, 12, and 24.

\begin{tabular}{lccc}
\hline Endpoint & Week 4 $(n=7298)$ & Week 12 $(n=6832)$ & Week 24 $(n=6573)$ \\
\hline DBP reduction $>10 \mathrm{mmHg}, n(\%)$ & $2162(29.6)$ & $3541(51.8)$ & $4254(64.7)$ \\
SBP reduction $>20 \mathrm{mmHg}, n(\%)$ & $1686(23.1)$ & $2899(42.4)$ & $3774(57.4)$ \\
SBP reduction $>20 \mathrm{mmHg}$ or DBP reduction & $2804(38.4)$ & $4413(64.6)$ & $5105(77.7)$ \\
$>10 \mathrm{mmHg}, n(\%)$ & & & $5527(84.1)$ \\
DBP $<90 \mathrm{mmHg}, n(\%)$ & $3830(52.5)$ & $5064(74.1)$ & $5243(79.8)$ \\
SBP $<140 \mathrm{mmHg}, n(\%)$ & $2747(37.6)$ & $4335(63.5)$ & $5956(90.6)$ \\
SBP $<140 \mathrm{mmHg}$ or DBP $<90 \mathrm{mmHg}, n(\%)$ & $4366(59.8)$ & $5553(81.3)$ & $6216(94.6)$ \\
Responder, $n(\%)^{*}$ & $4919(67.4)$ & $6022(88.1)$ & $4814(73.2)$ \\
Blood pressure controlled, $n(\%) \dagger$ & $2211(30.3)$ & $3846(56.3)$ & $-25.38 \pm 15.23$ \\
Reduction of blood pressure, mean \pm SD: & & & $-14.85 \pm 13.51$ \\
$\quad$ Systolic & $-15.27 \pm 14.10$ & $-21.17 \pm 14.90$ & $-12.54 \pm 14.17$ \\
$\quad$ Diastolic & $-9.12 \pm 9.79$ & & \\
\hline
\end{tabular}

Missing values among the intent-to-treat (ITT) population were 269 (3.6\%), 735 (9.7\%), and 994 (13.1\%) at week 4, week 12 , and week 24 , due to no blood pressure examinations.

${ }^{*}$ Responders were defined as those patients with SBP $<140 \mathrm{mmHg}$ and/or DBP $<90 \mathrm{mmHg}$, or a reduction of $>10 \mathrm{mmHg}$ in $\mathrm{DBP}$ and/or a reduction of $>20 \mathrm{mmHg}$ in SBP compared to baseline.

†Blood pressure controlled was defined as SBP $<140 \mathrm{mmHg}$ and DBP $<90 \mathrm{mmHg}$.

$\mathrm{DBP}=$ diastolic blood pressure; $\mathrm{SBP}=$ systolic blood pressure.

A significant Cohen's kappa of $0.755(P<0.001)$ showed moderate agreement for efficacy assessments between patients and physicians.

The global assessment for tolerability of valsartan/HCTZ SPC is summarized in Table 3.2. Again, almost all patients and physicians (96.8\%) reported good, very good, or excellent for the tolerability assessment, and $81.1 \%$ of the patients reported the same global assessments as their physicians. A significant Cohen's kappa of $0.768(P<0.001)$ showed moderate agreement for tolerability assessments between patients and physicians.

\section{Association Between Treatment Response and Age}

A significant association between age and response was found at week 4 ; the response rates were $65.6 \%$ for those younger than 50 years and

Table 3.1. Agreement of global assessment for efficacy by patients and physicians $(n=6705)$.

\begin{tabular}{lllllll}
\hline \multirow{2}{*}{ Assessment for efficacy } & & \multicolumn{4}{c}{ By patients $(n=6705)$} & \multirow{2}{*}{ Total } \\
\cline { 2 - 5 } & & Poor & Good & Very good & Excellent & $122(1.8)$ \\
By physicians, $n(\%)$ & Poor & $110(1.6)$ & $11(0.2)$ & $1(0.0)$ & $0(0.0)$ & $1503(22.4)$ \\
& Good & $73(1.1)$ & $1196(17.8)$ & $225(3.4)$ & $9(0.1)$ & $3317(49.5)$ \\
& Very good & $17(0.3)$ & $370(5.5)$ & $2,711(40.4)$ & $219(3.3)$ & $1763(26.3)$ \\
Total, $n(\%)$ & Excellent & $5(0.1)$ & $24(0.4)$ & $345(5.1)$ & $1389(20.7)$ & $1705(100.0)$ \\
\hline
\end{tabular}

$n=6705$, instead of 7567 , due to $862(11.4 \%)$ subjects in the intent-to-treat population who had no assessment for efficacy either by themselves or by physicians. 
Table 3.2. Agreement of global assessment for tolerability by patients and physicians $(n=6671)$.

\begin{tabular}{lllllll}
\hline & & \multicolumn{4}{c}{ By patients $(n=6671)$} \\
\cline { 2 - 5 } Assessment for tolerability & Poor & Good & Very good & Excellent & Total \\
\hline By physicians, $n(\%)$ & Poor & $112(1.7)$ & $14(0.2)$ & $2(0.0)$ & $0(0.0)$ & $128(1.9)$ \\
& Good & $68(1.0)$ & $1245(18.7)$ & $223(3.3)$ & $10(0.1)$ & $1546(23.2)$ \\
& Very good & $14(0.2)$ & $341(5.1)$ & $2,647(39.7)$ & $184(2.8)$ & $3186(47.8)$ \\
& Excellent & $4(0.1)$ & $35(0.5)$ & $341(5.1)$ & $1431(21.5)$ & $1811(27.1)$ \\
Total, $n(\%)$ & & $198(3.0)$ & $1635(24.5)$ & $3213(48.2)$ & $1625(24.4)$ & $6671(100.0)$ \\
\hline
\end{tabular}

$n=6671$ instead of 7567 because $896(11.8 \%)$ subjects in the intent-to-treat population had no assessment for tolerability either by themselves or by physicians.

$68.5 \%$ for others older than 50 years $(P=0.010)$. At week 12 and week 24, no significant association with age was found for response rate and BP control rate. For those patients younger than 50 years, DBP was reduced about $1 \mathrm{mmHg}$ more than in patients older than 50 years of age at all times measured $(P<0.001)$ (Supplementary Table 1).

\section{Association Between Treatment Response and Gender}

At week 4, the response rate and control rate in females was significantly higher than in males (response rate: $69.6 \%$ vs. $65.8 \%, P=0.001$; control rate: $32.9 \%$ vs. $28.4 \%, P<0.001$ ), and SBP reduction in females was significantly greater than that in males $(-15.96 \pm 14.73$ vs. $-14.79 \pm 13.62 \mathrm{mmHg}, P=0.001$ ). At weeks 12 and 24 , DBP reduction in females was significantly less than that in males $(-11.89 \pm 18.25$ vs. $-12.99 \pm 10.37 \mathrm{mmHg}$ at week $12, P=0.002$; $-14.45 \pm 10.21$ vs. $-15.13 \pm 15.40 \mathrm{mmHg}$ at week 24, $P=0.046$ ) (Table 4).

\section{Safety of Valsartan/HCTZ SPC}

The safety of valsartan/HCTZ SPC was assessed by the number of adverse events that occurred during the study period. A total of 1747 adverse events were recorded for patients who took valsartan/HCTZ SPC at least once, and of these events, 1582 (90.6\%) were thought to be unrelated to the study drug. Among the 7567 patients, 1082 patients (14.3\%) experienced at least one adverse event, 262 patients (3.46\%) reported two adverse events, and 152 patients (2.01\%) reported more than two adverse events. Four $(0.23 \%)$ serious adverse events were reported, including coronary artery disease, hypoglycemia, non-ST elevation myocardial infarction, and upper gastrointestinal bleeding. None of these serious adverse events were suspected to be due to valsartan/HCTZ SPC administration.

\section{DISCUSSION}

In this multinational observational study, significant SBP and DBP reduction was found at all time points during the study, with early achievement of the BP goal (140.7/87.2 mmHg, at week 4) and additional significant reduction at weeks 12 and 24. By the end of the study (week 24), almost all (94.6\%) patients were responsive to valsartan/HCTZ SPC, and 73.2\% of these responsive patients achieved the desired degree of BP control. Based on the proportion of patients achieving the desired SBP and DBP values, valsartan/HCTZ SPC exhibited a high 

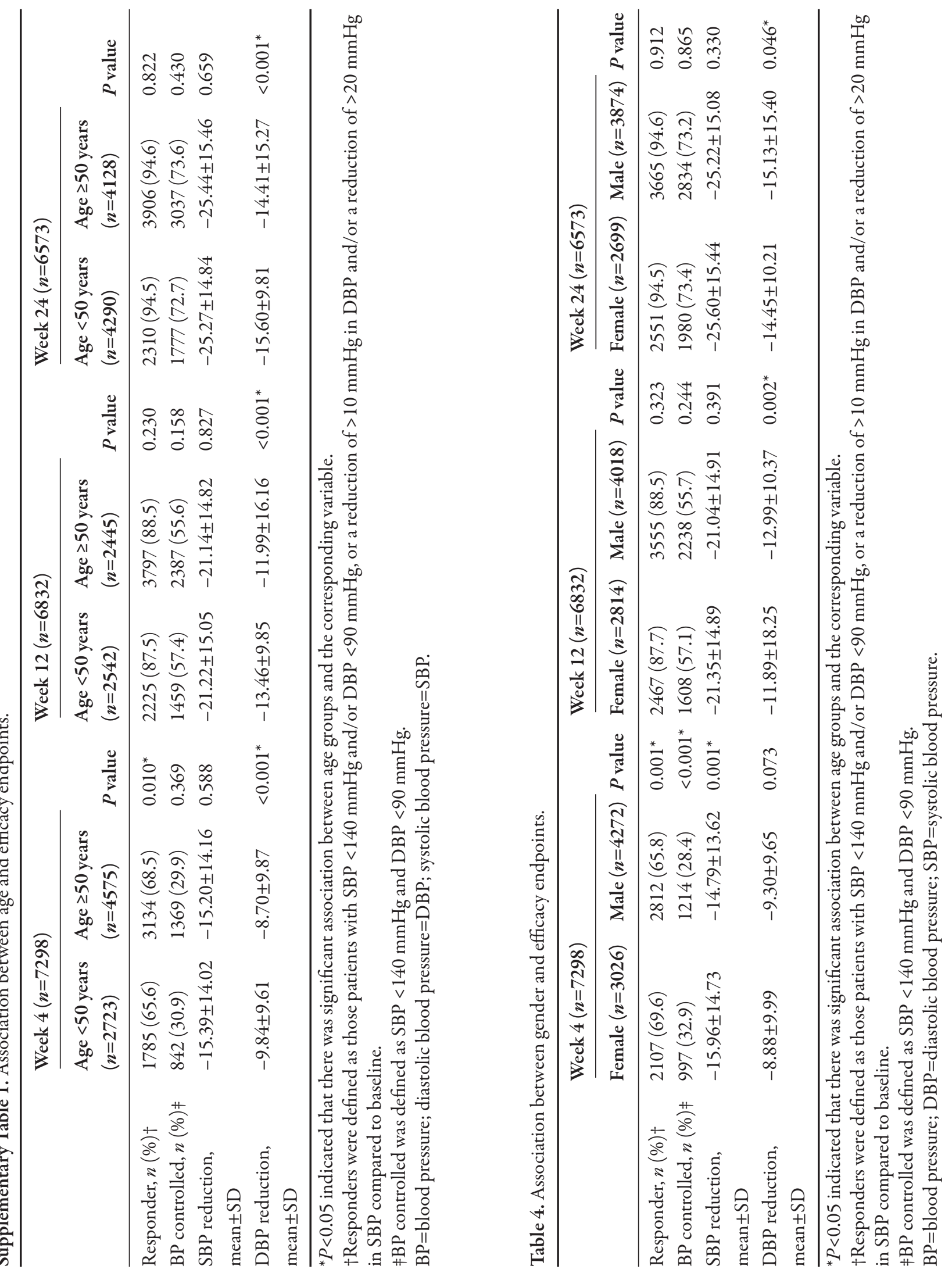
degree of efficacy in this population (that is, in Asian adults, male and female naïve patients with stage 1 or stage 2 hypertension, or who were poorly controlled on their respective ongoing monotherapy or combination therapy).

Results of population studies vary by countries, as well as different prescription behaviors. Low prescription rates for combination therapy, $42.2 \%$ and $35.3 \%$, were reported in studies from India and Japan, respectively, and ARB/ HCTZ was not the most popular combination selected. ${ }^{18,19}$ In contrast, more than half (64\%) of US hypertensive patients were prescribed combination therapy, with the majority of these prescriptions (27\%) as ARB or ACEI in combination with diuretics. ${ }^{20}$

A previous descriptive cross-sectional study reported that only $59 \%$ of hypertensive patients were under adequate control with treatment. ${ }^{21}$ A meta-analysis of several randomized, double-blind studies comparing valsartan monotreatment with combination treatment ${ }^{22}$ concluded that combination therapy was more effective in terms of response rate.

In the current study, we noticed that the younger patients ( $<50$ years old) showed more DBP reduction than older patients. However, a current study by Asmar and Oparil showed older patients ( $>65$ years old) achieve a greater DBP reduction than younger patients. ${ }^{23}$ Although the difference was only $1 \mathrm{mmHg}$, it was statistically significant. The correlation between age and BP reduction will require additional confirmation in future investigations, and the clinical interpretation should be further discussed.

Regardless, in the current study, females showed a significantly smaller DBP reduction than males at week 12 and week 24. However, the difference between males and females was only $1 \mathrm{mmHg}$, and the significance is marginal at week 24. In the Asmar and Oparil study, females also showed a $1 \mathrm{mmHg}$ smaller DBP reduction than males, but this difference was not statistically significant. ${ }^{23}$

Treatment with valsartan/HCTZ SPC was well tolerated for most patients, and almost all patients rated the tolerability with good or better. Almost all patients also rated the combination as efficacious, but because mild hypertension is symptomless, this subjective judgment reflected whether the patient's BP had reached a value the patient thought acceptable, rather than whether actual control had been achieved.

Choice of antihypertensive drugs depends on cost, anticipated side effects, and the physician's familiarity with the drug. Clinical trials have shown valsartan/HCTZ to be more effective than either drug alone and to have an adverse effect profile similar to that of placebo. ${ }^{19}$ The current study is the largest study to date, and includes 7567 Asian patients in a general clinical practice setting treated with valsartan/HCTZ SPC. The results reflect a real life situation as the patients included in this study represent the general population being prescribed valsartan/HCTZ SPC specifically in the Asia-Pacific region. The low incidence of adverse effects confirmed the safety of treatment in this study cohort. The results also confirm that combination therapy as first-line approach in stage 2 hypertension as recommended by $\mathrm{WHO}$ and the $\mathrm{JNC}^{8}$ is efficacious and well tolerated in Asian patients. However, $45 \%$ of the patients in the study had stage 1 hypertension, and because we did not investigate thiazide monotherapy, we cannot say whether valsartan/HCTZ is more efficacious than thiazide monotherapy in stage 1 hypertension. But in cases where two drugs need to be prescribed, it has been demonstrated that SPC treatment is associated with better compliance and a smaller pill burden. Antihypertensive therapy is always long lasting. Further research is required with this drug combination in Asian hypertension patients beyond 24 weeks of treatment in order 
to confirm that the benevolent safety profile and efficacy can be maintained in the long run. Whether first line combination therapy has an effect on the number of therapies required in the future in order to obtain BP control will also be in the area of interest.

One limitation of the study was that there was a lack of data on patients who changed their nonstudy antihypertensive drug(s) during the course of the study. Another is that there was insufficient data necessary to perform subgroup analyses.

\section{CONCLUSION}

In summary, this multicenter, multicountry study consisting of 7567 Asian patients with essential hypertension, demonstrated valsartan/ HCTZ SPC to be highly effective, well tolerated, and devoid of any serious adverse effects in a general practice setting.

\section{ACKNOWLEDGMENTS}

We thank the study participants and their families for their personal time and commitment to this project. The current study was sponsored by Novartis, Inc. for postmarketing surveillance of valsartan/HCTZ SPC with regards of its efficacy, tolerability, and safety profiles in AsiaPacific patients. JW and ND are employees of Novartis and are therefore eligible for Novartis stock and stock options. W-TL and J-EP have received research grants and investigator fees from Novartis. The authors have no conflicts of interest to declare.

Open Access. This article is distributed under the terms of the Creative Commons Attribution Noncommercial License which permits any noncommercial use, distribution, and reproduction in any medium, provided the original author(s) and source are credited.

\section{REFERENCES}

1. Whelton PK, Beevers DG, Sonkodi S. Strategies for improvement of awareness, treatment and control of hypertension: results of a panel discussion. J Hum Hypertens. 2004;18:563-565.

2. Singh RB, Suh IL, Singh VP, et al. Hypertension and stroke in Asia: prevalence, control and strategies in developing countries for prevention. J Hum Hypertens. 2000;14:749-763.

3. Ruilope LM, Burnier M, Muszbek N, et al. Public health value of fixed-dose combinations in hypertension. Blood Press Suppl. 2008;1:5-14.

4. Volpe M, Tocci G. 2007 ESH/ESC Guidelines for the management of hypertension, from theory to practice: global cardiovascular risk concept. J Hypertens. 2009;27(Suppl. 3):S3-11.

5. Mendis S, Abegunde D, Oladapo O, Celletti F, Nordet P. Barriers to management of cardiovascular risk in a low-resource setting using hypertension as an entry point. J Hypertens. 2004;22:59-64.

6. Dusing R, Handrock R, Klebs S, Tousset E, Vrijeno B. Impact of supportive measures on drug adherence in patients with essential hypertension treated with valsartan: the randomized, open-label, parallel group study VALIDATE. J Hypertens. 2009;27:894901.

7. Frank J. Managing hypertension using combination therapy. Am Fam Physician. 2008;77:1279-1286.

8. Chobanian AV, Bakris GL, Black HR, et al. The Seventh Report of the Joint National Committee on Prevention, Detection, Evaluation, and Treatment of High Blood Pressure: the JNC 7 report. JAMA. 2003;289:2560-2572.

9. Mistry NB, Westheim AS, Kjeldsen SE. The angiotensin receptor antagonist valsartan: a review of the literature with a focus on clinical trials. Expert Opin Pharmacother. 2006;7:575-581.

10. Fanestil DD, Vaughn DA, Ma L, Hyde RH, Printz MP. Thiazide diuretics normalize urinary calcium in spontaneously hypertensive male rats. Kidney Int. 1997;51:1018-1021.

11. Melby JC. Selected mechanisms of diuretic-induced electrolyte changes. Am J Cardiol. 1986; 58:1A-4A.

12. Motwani JG. Combining renin-angiotensinaldosterone system blockade with diuretic therapy for treatment of hypertension. J Renin Angiotensin Aldosterone Syst. 2002;3:72-78. 
13. Black HR, Levy DG, Crikedair N, Rocha R. Predicting age- and dose-related responses to antihypertensive therapy: pooled analysis of two randomized clinical trials of valsartan alone and combined with hydrochlorothiazide. J Am Soc Hypertension. 2008;2:476-483.

14. Calhoun DA, Glazer RD, Pettyjohn FS, Coenen PDM, Zhao Y, Grosso A. Efficacy and tolerability of combiation therapy with valsartan/ hydrochlorothiazide in the initial treatment of severe hypertension. Curr Med Res Opin. 24;8:2303-2311.

15. Weinberger MH, Glazer RD Crikelair NA, Chiang YT. Achieving blood pressure goal: initial therapy with valsartan/hydrochlorothiazide combination compared to monotherapy. J Hum Hypertens. 2010;24:823-830

16. Pool JL, Glazer R, Crikelair N, Levy D. The role of baseline blood pressure in guiding treatment choice. A secondary analysis of the use of valsartan/hydrochlorothiazide as initial therapy in hypertensive adults in a randomized, double blind, placebo-controlled trial. Clin Drug Invest. 2009;29:791-802.

17. National Heart Lung and Blood Institute. The Seventh Report of the Joint National Committee on Prevention, Detection, Evaluation, and Treatment of High Blood Pressure (JNC 7). Available at: www. nhlbi.nih.gov/guidelines/hypertension/. Accessed March 14, 2011.
18. Tiwari H, Kumar A, Kulkarni SK. Prescription monitoring of anti-hypertensive drug utilization at the Panjab University Health Centre in India. Singapore Med J. 2004;45:117-120.

19. Mori H, Ukai H, Yamamoto H, et al. Current status of antihypertensive prescription and associated blood pressure control in Japan. Hypertens Res. 2006;29:143-151.

20. Ma J, Lee KV, Stafford RS. Changes in antihypertensive prescribing during US outpatient visits for uncomplicated hypertension between 1993 and 2004. Hypertension. 2006; 48;846-852.

21. Tardif JC, Curnew GP, Leclerc JM, Rehel B. Reaching the therapeutic goal in hypertension: results from the Canadian valsartan observational study. (Diovantage 4). Can J Clin Pharmacol. 2008;15:e177-e187.

22. Weir MR, Crikelair N, Levy D, Rocha R, Kuturu $\mathrm{V}$, Glazer R. Evaluation of the dose response with valsartan and valsartan/hydrochlorothiazide in patients with essential hypertension. J Clin Hypertens (Greenwich). 2007;9:103-112.

23. Asmar R, Oparil S. Comparison of the antihypertensive efficacy of irbesartan/HCTZ and valsartan/HCTZ combination therapy: impact of age and gender. Clin Exp Hypertens. 2010;32:499-503. 